\title{
Motives for consumer choice of traditional food and European food in mainland China
}

(C) <2015> . This manuscript version is made available under the CC-BY-NC-ND 4.0

license http://creativecommons.org/licenses/by-nc-nd/4.0/

\section{Citation}

Wang, O., De Steur, H., Gellynck, X., \& Verbeke, W. (2015). Motives for consumer choice of traditional food and European food in mainland China. Appetite, 87, 143-151. https://doi.org/10.1016/j.appet.2014.12.211 Ou Wang ${ }^{1,2^{*}}$, Hans De Steur ${ }^{1}$, Xavier Gellynck ${ }^{1}$, Wim Verbeke ${ }^{1}$

${ }^{1}$ Department of Agricultural Economics, Ghent University, Coupure links 653, B9000 Gent, Belgium.

${ }^{2}$ Waikato Management School, University of Waikato, Hamilton 3240, New Zealand

*Corresponding author: Ou Wang, ou.wang@waikato.ac.nz 
- Presents a Food Choice Questionnaire-based study in mainland China

- Proposes a novel construct with six food choice motive dimensions

- “Time or money saving" and "Sensory appeal" are key food choice motives

- Traditional food choices are driven by "Availability and familiarity"

- Preference for European food is linked to "Mood" motives 
1 Motives for consumer choice of traditional food and European food in mainland China

\section{Abstract}

6 increasing dramatically during the last decade. Nevertheless, European food producers

7 often appear to be not capable to fully exploit this huge market potential, partially due

8 to the competition with traditional (Chinese) foods. This study examines the

9 determinants of mainland Chinese consumers' choice of traditional food and

10 European food. A web-based survey was administered with 541 consumers from two

11 cities: Shanghai and Xi'an. Thereby, the Food Choice Motives model, predominantly

12 used thus far in a European or developed context, is applied to mainland China in

13 order to address the lack of knowledge on food motives of its consumer market and to

14 detect associations between these motives, attitudes, and purchase intentions.

15 Factor analysis resulted in a new Food Choice Motive construct that is 16 considered more appropriate within the context of mainland Chinese consumers, 17 encompassing six dimensions: Health concern, Time or money saving, Sensory appeal, 18 Availability and familiarity, Mood and Food safety concern. Path analysis 19 demonstrated that Time or money saving was negatively associated with attitude

20 toward traditional food on the one hand and purchase intentions toward European

21 food on the other hand. Availability and familiarity had a positive association with

22 attitude toward traditional food. Mood was a positive factor driving attitude toward 
23 European food. For both food types, Sensory appeal and Attitude were positively

24 linked to purchase intentions. Furthermore, Mood was negatively linked to the 25 purchase intention toward traditional food in Shanghai. Food safety concern was 26 positively associated with attitudes toward traditional food in Xi'an.

27 This study contributes to a better understanding of mainland Chinese 28 consumers as well as the key factors that play a role in their choices for traditional 29 (Chinese) food and European food. As such, these findings could support European 30 food producers when developing marketing strategies for more effectively reaching 31 Chinese consumers.

\section{Keywords}

34 China, Consumer, Traditional food, European food, Food choice motives, Path 35 analysis 
Due to the growing income levels, its huge consumer market, the changing

51 dietary habits and the Westernization of food consumption patterns in particular, and

52 since its accession to the World Trade Organization in 2003 (WTO), mainland China

53 became more and more important as a (potential) market for food producers around

54 the world, especially from European countries (Curtis, Mccluskey, \& Wahl, 2007; Hu,

55 Cox, \& Edwards, 2007; Pingali, 2007; World Bank, 2014). This is particularly the

56 case in the past years, as the annual growth rate of $27.3 \%$ for imported, processed

57 foods/beverages between 2008 and 2012 in mainland China shows (Alice, 2013). As a

58 consequence, China quickly became the largest wine export market of the European

59 Union (EU), for example (Alinna, 2013). And the Chinese food market is likely to

60 become even more oriented toward European foods in the future.

61 Opposite to this trend, European food producers face strong competition from

62 food producers in mainland China. Given the thousands of local traditional foods that

63 still determine the modern Chinese diet (Cai \& Situ, 2006; Cheng, 1994; Zhang,

64 Zhang, Tang, Zou, \& Su, 2009; Zhao, 2003), and the cultural dietary differences

65 between Chinese and Western consumer behavior (Chang, Kivela, \& Mak, 2010; Sun

66 \& Collins, 2004; Wan, 1995; Zhang et al., 2011), European and Western producers of

67 traditional foods are continuously seeking potential ways to successfully penetrate this

68 promising market. Nevertheless, there is still a lack of understanding of mainland

69 Chinese consumers' motives for their own traditional foods versus European foods.

70 When analyzing food choice motives, the work of Steptoe, Pollard, and 
71 Wardle (1995) is indispensable. In their Food Choice Questionnaire (FCQ), they

72 classified food choice motives (FCMs) into nine dimensions: Health, Mood,

73 Convenience, Sensory appeal, Natural content, Price, Weight control, Familiarity and

74 Ethical concern. This FCQ was widely used by researchers to explore choice motives

75 of consumers with different cultural backgrounds for different food products (Chen,

76 2011; Honkanen, 2010; Honkanen \& Frewer, 2009; Johansen, Næs, \& Hersleth, 2011;

77 Pieniak, Verbeke, Vanhonacker, Guerrero, \& Hersleth, 2009; Pohjanheimo,

78 Paasovaara, Luomala, \& Sandell, 2010; Pula, Parks, \& Ross, 2014; Sproesser,

79 Strohbach, Schupp, \& Renner, 2011; Vyth et al., 2010; Zakowska-Biemans, 2011).

80 Several studies focused on traditional food products, mostly in Europe (Almli,

81 Verbeke, Vanhonacker, Næs, \& Hersleth, 2011; Guerrero et al., 2010; Guerrero et al.,

82 2012; Guerrero et al., 2009; Pieniak et al., 2009; Vanhonacker, Lengard, Hersleth, \&

83 Verbeke, 2010; Vanhonacker, Verbeke, et al., 2010). The study by Almli et al. (2011)

84 showed that product attributes related to sensory, health and quality issues helped

85 European consumers to create a positive image of traditional foods, whereas product

86 attributes like convenience or price, had a negative effect on their perception. Pieniak

87 et al. (2009) reported that the most important motives for European consumers to

88 choose traditional foods were: Weight control, Convenience, Familiarity, Healthiness

89 and Natural content. However, until now, few empirical studies have examined

90 Chinese consumers' choice motives for European foods. Whereas Curtis et al. (2007)

91 found that 'taste' has a large impact on Chinese consumers' preferences for Western-

92 style convenience foods, Li, Lai, Harrill, Kline, and Wang (2011) mentioned that 
93 Chinese outbound travelers were very sensitive to the cleanliness / safety and price of

94 local foods when visiting Western countries. Chinese tourists mainly looked at 95 appetizing assurance and familiar flavor when choosing Australian local food (Chang 96 et al., 2010). Notwithstanding the usefulness of their findings, none of these studies 97 used a model like a FCQ-based model, to comprehensively analyze and understand 98 mainland Chinese consumers' FCMs as well as their choice motives for traditional 99 Chinese food and European food.

100 Given the aforementioned research gaps, the aim of this study is to examine 101 the association between FCMs and mainland Chinese consumers' attitudes and 102 purchase intentions toward their own traditional food and European food. This allows 103 for comparison of consumer behavior for two distinct types of food, local, traditional 104 food versus European foods in mainland China. Thereby, 'European food' was 105 defined as 'local food products imported from Europe or food with a European style 106 or flavor that can be consumed in restaurants or other places in China'. Building upon 107 the FCQ and theoretical models on food choice motives and consumer behavior 108 (attitudes, purchase intentions, consumption) (Ajzen, 1991; Chen, 2007; Pieniak et al., 109 2009; Zakowska-Biemans, 2011; Žeželj, Milošević, Stojanović, \& Ognjanov, 2012), a 110 hypothetical model was developed, as shown in Figure 1. FCMs are assumed to have 111 a direct impact on consumer attitudes and purchase intentions (willingness to buy) of 112 both food types. Meanwhile, FCMs are also expected to indirectly influence the 113 purchase intentions through attitude. As previous FCQ-based studies have shown that 114 the applicability of FCM constructs differs according to the cultural setting 
115 (Honkanen, 2010; Honkanen \& Frewer, 2009; Milošević, Žeželj, Gorton, \& Barjolle,

116 2012; Pula et al., 2014; Zakowska-Biemans, 2011; Žeželj et al., 2012), we assessed

117 the generalizability of the original construct of FCMs (Steptoe et al., 1995) to a

118 consumer sample obtained from mainland China.

$120>$ > Insert Figure 1

\section{Materials and methods}

\subsection{Participants and procedures}

The data collection was conducted by a Chinese market research agency in

125 December 2013. A web-based questionnaire was sent to registered members of a consumer panel maintained by the research agency, using strict identification

127 verification. The study was done in two mainland Chinese cities: Shanghai and Xi'an.

128 All participants who completed the questionnaire received a monetary incentive.

130 Shanghai in Northern and Xi'an in Southern China. Besides obvious differences

131 between both regions in terms of cultural history, dietary habits and lifestyles, there

132 are also differences in consumption behavior between this low and high income

133 region (He, 2013; Sun \& Collins, 2004; Sun, 2012).

Being an international metropolis and the most developed city of mainland

135 China, Shanghai has gained most exposure to Western (food) cultures in mainland

136 China, while Xi' an is a more traditional city in a less developed region with far lower 
137 per capita income (Liu et al., 2011; National Bureau of Statistics of the People's 138 Republic of China, 2013).

140 Shanghai and 282 from Xi'an. Table 1 presents the detailed socio-demographic 141 characteristics of the pooled sample and the subsamples, including age, gender, 142 financial situation of the household and occupation. In line with previous research 143 (Pieniak et al., 2009), the financial situation of households was subjectively assessed 144 by participants on a 7-point interval scale ranging from 'difficult' to 'well off'. 145

$146>$ Insert Table 1

\subsection{Pretest}

The questionnaire was initially developed in English and translated into 150 Chinese. Two rounds of online pretests were carried out with Chinese participants 151 living in China and working in Belgium. Apart from completing the questionnaire, 152 these participants were asked to provide feedback about the design and interpretation 153 of the questionnaire. Based on the results and feedback, the survey design and 154 Chinese translation were adapted.

\subsection{Measures}


161 original FCM items were considered in this study. We have followed the selection 162 strategy of Pieniak et al. (2009), in which only the most appropriate and relevant FCM 163 dimensions and items are included based on a prior qualitative study. Prior to this 164 study, a word association test was conducted to explore Chinese consumer 165 perceptions of traditional food and European food in 2012 (Wang, Gellynck, Liu, Liu, 166 Zhang, Vanhonacker, \& Verbeke, 2014). In line with Hawkins and Mothersbaugh 167 (2009), who pointed out that consumer perceptions of marketing stimuli of a product 168 are influenced by motives, items and dimensions were selected based on the 169 frequencies of the terms that participants associated with the stimulus words 170 'traditional food' and 'European food'. For example, because none of the participants 171 related both stimulus words with ethical concern, political issues and environmental 172 protection issues, the overall FCM dimension of Ethical concern and its underlying 173 items were excluded in the present study. As a consequence, eight FCM dimensions 174 from the original FCQ were included to examine participants' motives for food 175 choices: Sensory appeal, Convenience, Mood, Weight control, Natural content, Price, 176 Health and Familiarity. This results in a total of twenty-seven original FCM items 177 (Table 2). Participants were asked to evaluate the importance of these items for their 178 daily food choice ('It is important to me that the food I eat on a typical day 179 is/contains...'), on a seven-point Likert scale: 1= disagree strongly, $2=$ disagree 180 moderately, $3=$ disagree slightly, $4=$ neither agree nor disagree, $5=$ agree slightly, $6=$ 
181 agree moderately, and 7= agree strongly (Prescott, Young, O'Neill, Yau, \& Stevens, 182 2002).

183

$184>$ Insert Table 2

185

186

Participants' attitudes toward traditional food and European food were

187 assessed by respectively three seven-point semantic differential scales using bipolar 188 adjectives: unhappy/happy, dull/excited, and terrible/delighted (Table 3). This method 189 had been employed in previous FCQ-based studies assessing consumers' general 190 attitudes toward food products (Pieniak et al., 2009; Žeželj et al., 2012). Items measuring purchase intentions (willingness to buy) were derived from a 192 study by Klein, Ettenson, and Morris (1998), which examined mainland Chinese 193 consumers' purchase intentions (willingness to buy) toward Japanese products. 194 Participants were asked to indicate their agreement with the statements: (1) 'I would 195 never buy a [food category] (R).' (2) 'Whenever available, I would prefer to buy 196 [food category].' and (3) 'Whenever possible, I would avoid buying [food category] 197 (R).' (Table 3). Each of these three statements were asked for traditional food and 198 European food, and assessed on a seven-point interval scale with the same response 199 categories as in the evaluation part of the FCMs. The two reverse-scored items were 200 recoded before data analysis.

$202>>$ Insert Table 3 


\section{Data analysis and results}

205

\subsection{Analysis methods}

206

The statistical software tools SPSS 22 and AMOS 21 were used for

207 performing all analyses in this research. With respect to the generalizability of the

208 original construct of FCMs (i.e. the eight dimensions, as shown in Table 2) for the

209 specific case of our mainland Chinese sample, the analysis methods were similar as in

210 the FCQ-based studies presented by Eertmans, Victoir, Notelaers, Vansant, \& Van

211 den Bergh (2006) and Milošević et al. (2012). First, confirmatory factor analysis

212 (CFA) was used to examine whether the original FCM construct has a good fit with

213 the pooled sample and the samples of the two cities (AMOS 21); second, as the

214 construct did not fit well with the samples, exploratory factor analysis was conducted

215 to explore the appropriateness of the construct of FCMs for the specific Chinese

216 sample. Principal component analysis (PCA) with varimax rotation was used (SPSS

$217 \quad 22)$

218 Structural equation modeling (SEM) was used to assess the association

219 between the FCM variables of the new FCM construct and the attitude and purchase

220 intention variables related to traditional food and European food, based on two

221 previous FCQ-based studies (Pieniak et al., 2009; Žeželj et al., 2012). Path analysis

222 for the pooled sample and multi-group path analysis for the two city subsamples were

223 conducted to detect significant relationships among the latent variables of FCM 
dimensions, attitudes and purchase intentions as well as to identify if the data of the

225 two cities were suitable to analyze them together (AMOS 21) (Wu, 2009).

As Rigdon (1995) indicated that Chi-square may not be an appropriate measure of goodness-of-fit for a SEM, due to the complicated structure, large amount

228

229 230

241 (Steptoe et al., 1995). In this study, CFA was used for the pooled sample and the 242 samples of two cities to determine if the original FCM construct is apprpriate for our 243 mainland Chinese sample. As shown in Table 4, the goodness of fit is poor for either 244 the pooled sample or the samples of two cities. The values of all indices were outside 245 of what is acceptable. Values of RMSEA were above 0.08 , CFI and IFI values were 
246 below 0.9 , and $\mathrm{NC}$ values were above 3. Therefore, the original FCM construct is not 247 suitable for our specific sample.

248

249 >> Insert Table 4

250

Besides, in a CFA, factor loadings (standardized regression weights of items)

252 should be between 0.5 and 0.95 for items to actually reflect the theoretical latent 253 construct they are designed to evaluate (Hair, Black, Babin, \& Anderson, 2014; Wu, 254 2009). In our case, the item 'Is good value for money' had very low factor loadings in 255 either the pooled sample or samples of the two cities (pooled sample 0.362, Shanghai 256 sample 0.387 , Xi'an sample 0.335 ). The factor loadings of the other 26 items varied 257 between 0.502 and 0.845 for the pooled sample, between 0.443 and 0.841 for the 258 Shanghai sample and between 0.503 and 0.843 for the $\mathrm{Xi}$ 'an sample. The low factor 259 loading of 'Is good value for money' FCM in the dimension Price is in line with 260 previous FCQ-based studies (Honkanen \& Frewer, 2009; Januszewska, Pieniak, \& 261 Verbeke, 2011; Milošević et al., 2012; Pieniak et al., 2009; Pohjanheimo et al., 2010; 262 Roos, Lehto, \& Ray, 2012). It seems that this item should not be considered as an 263 appropriate survey question for examining the FCM dimension Price. Therefore, 264 Price and Value for money were treated as two separate food choice motive 265 dimensions in the study by Brunner, van der Horst, and Siegrist (2010). Kornelis, Van 266 Herpen, Van der Lans, and Aramyan (2010) also pointed out that the item 'Is good 267 value for money' did not contribute to the measurement of the price dimension, 
268 because of its focus on the price-quality assessment, as compared to the price 269 assessment of two other items. As a consequence, we did not include this item in our 270 statistical analyses.

\subsection{Principal component analysis (PCA)}

A PCA with varimax rotation was conducted to explore the construct of 26

274 FCM items for the pooled sample. A new construct with six dimensions was 275 identified. The item 'Is like the food I ate when I was a child' did not load well on any 276 dimension (with factor loadings below 0.50). This item may be more suitable for 277 examining the concept 'Symbolic value of a food to people', an extra value of some 278 special food products, such as traditional food or ethnic food (Lupton, 1994; 279 Vanhonacker, Lengard, et al., 2010; Verbeke \& Lopez, 2005; Zhou \& Hui, 2003). 280 None of the other 25 items were related to the Symbolic value dimension. Therefore, 281 the item 'Is like the food I ate when I was a child' was deleted from the new FCM 282 construct and was not incorporated in the analyses.

284 Reliabilities of these six dimensions are relatively high given that they all have a 285 Cronbach's $\alpha$ score above 0.60 (Žeželj et al., 2012).

$287>$ Insert Table 5 

contain the same items as in the original FCM construct. FCM dimensions Health and Weight control, and one item from the original dimension Natural content, namely 'Contains natural ingredients'. It seems that there 295 is no clear distinction between the concepts of Health and Weight control in mainland Chinese consumers' minds. Third, the other two items of the original dimension Natural content, namely 298 299 300 events suddenly emerged in mainland China, leading to increased concerns of 302 consumers with regard to food safety (Ortega, Wang, Wu, \& Olynk, 2011; Qiao, Guo, 303 \& Klein, 2012; Liu, Pianiak, \& Verbeke, 2013; 2014). Furthermore, some of these 304 food safety events were specifically related to the problems of artificial ingredients or 305 additives in food products (Tang, 2013; Zhang, An, \& Zhang, 2013). To this end, we 306 defined this new dimension as Food safety concern. Fourth, similar with some previous FCQ-based studies, the five items of the 308 original FCM dimension Convenience loaded on different dimensions in the new 309 FCM construct (Honkanen \& Frewer, 2009; Milošević et al., 2012). Among them, 310 three items with a semantic meaning about preparing food in a simply way, loaded on 311 a new dimension with two items of another original FCM dimension Price. We 
312 named this new dimension Time or money saving. This dimension reflects a food

313 choice motive about purchasing simple and everyday food to gain time and reduce 314 costs.

315 Finally, the two other items of the original FCM dimension Convenience, 316 dealing with the availability to purchase food, loaded on another new dimension with 317 two items from the original FCM dimension Familiarity. This new dimension is 318 defined as Availability and familiarity, and represents a Chinese consumer food 319 choice motive about buying daily foods which are familiar or available in familiar 320 markets.

\subsection{Path analysis}

A structural equation model (SEM) was built to assess the association between

324 the FCMs and the attitudes and purchase intentions toward traditional food and 325 European food (see Figure 2). The model included ten latent variables, the six new 326 FCM dimensions and the attitudes and purchase intentions toward the two types of 327 foods. These latent variables encompass 37 observed variables. The observed 328 variables of the four latent variables about attitudes and purchase intentions have good 329 internal reliabilities, with high Cronbach $\alpha$ scores: 0.859 for the attitudes toward 330 traditional food, 0.675 for the purchase intentions (willingness to buy) toward 331 traditional food, 0.928 for the attitudes toward European food and 0.796 for the 332 purchase intentions (willingness to buy) toward European food (Žeželj et al., 2012). 
$>>$ Insert Figure 2

Path analysis was conducted for the pooled sample. The SEM was modified through correlating the error variables between two FCM items 'Is cheap' and 'Is not expensive' because these items refer to a similar issue and because the values of modification indices were much higher than the values between other FCM items

340 (Anderson \& Gerbing, 1988; Byrne, 2001; Wu, 2009). Regarding the goodness-of-fit 341 indices for the path analysis, the modification lead to a substantial decrease in Chi342 Square value, which further justifies the modification (Byrne, 2001; Wu, 2009). Table 3436 shows the goodness-of-fit indices for this path analysis. The SEM performed well in 344 the path analysis, as the values of all indices were within the acceptance limits: below 3450.08 for RMSEA, above 0.9 for CFI and IFI and below 3 for NC (Table 6). 346 Furthermore, multi-group path analysis was conducted for the samples of two cities 347 based on the SEM after modification. The RMSEA and NC values indicated an 348 acceptable fit for all restricted models (RMSEA, from 0.040 to 0.041 ; and NC, from 3491.887 to 1.899 ); while only the CFI and IFI values were suboptimal (CFI, from 0.880 350 to 0.889 ; and IFI, from 0.880 to 0.891 ) (Žeželj et al., 2012). However, as Olsen, 351 Scholderer, Brunsø, and Verbeke (2007) suggested, the RMSEA values of restricted 352 models are a sufficient indicator for justifying the decision to pool the data. Moreover, 353 RMSEA values are also considered a better indicator than other indices for model-fit 354 evaluation (Marsh \& Balla, 1994; Wu, 2009). This underpins our decision to pool our 355 data in order to detect significant paths between the FCM dimensions and the attitudes 
356 and purchase intentions toward traditional food and European food.

$358>$ Insert Table 6

Figure 3 shows the significant paths of the SEM, with standardized regression

361 weights, for the pooled sample and the samples of two cities. Generally speaking, for 362 either the pooled sample or the samples of two cities, consumers' attitudes were 363 positively and strongly associated with their purchase intention toward both 364 traditional food and European food. This means that the FCM factors, which directly 365 influence consumers' attitudes, would also indirectly influence their purchase 366 intentions toward both types of foods (Ajzen, 1991; Chen, 2007; Pieniak et al., 2009). With regard to the pooled sample, consumers' attitude toward traditional food 368 was positively linked to the FCM dimension Availability and familiarity, and 369 negatively linked to Time or money saving. In other words, those mainland Chinese 370 consumers who attached more importance to daily food purchases in order to save 371 time or money had less positive attitudes toward traditional foods. By contrast, people 372 who preferred to buy familiar foods or foods in familiar market places had more 373 positive attitudes toward traditional food. Furthermore, consumers' attitude for 374 European food was positively associated with Mood. So, those mainland Chinese 375 consumers who often chose foods for relaxing or easing stress were more likely to 376 have a positive attitude toward European food. Moreover, the FCM dimension 377 Sensory appeal was recognized to have positively direct relationships with 
$394>$ Insert Figure 3

398 dimensions to evaluate food choice motives with consumers from mainland China.

399 Moreover, it evaluates its applicability by targeting two distinct food types, Chinese 
401 China, with high degree of development) and Xi'an (Northern China, with a lower 402 degree of development and less developed). The original FCQ is considered a 403 comprehensive and reliable tool to explore consumers' daily food choice motives, but 404 was initially developed through research in a Western (European) setting (Fotopoulos, 405 Krystallis, Vassallo, and Pagiaslis \& 2009; Steptoe et al., 1995). As such, previous 406 studies indicated that the FCM constructs of the original FCQ cannot be totally 407 replicated across different countries or regions (Eertmans et al., 2006; Fotopoulos et 408 al., 2009; Milošević et al., 2012; Pula et al., 2014). Indeed, the result of our 409 confirmatory analysis in this study confirmed that the original FCM construct 410 (dimension Ethical concern was not included) is not appropriate for analyzing FCM 411 in mainland China. By using exploratory factor analysis, a novel, more suitable FCM 412 construct was revealed for the mainland Chinese sample, characterized by six 413 dimensions: Health concern, Time or money saving, Sensory appeal, Availability and 414 familiarity, Mood and Food safety concern. Based on this new FCM construct, a 415 structural equation model for path analysis provided a good fit to identify associations 416 between mainland Chinese consumers' food choice motives and their attitudes and 417 purchase intentions toward traditional food and European food.

418 With respect to the motivation factors that drive mainland Chinese consumers 419 to choose traditional food, five factors had a direct or indirect effect, either in the 420 pooled sample or a city subsample: Time or money saving (negatively related to the 421 choice of traditional food), Sensory appeal (positively related), Availability and 
422 familiarity (positively related), Mood (negatively related in Shanghai) and Food safety

423 concern (positively related in Xi'an). This is partially in line with previous consumer-

424 based studies related to traditional food in Europe, where Sensory appeal and the

425 assurance of safety and quality were key factors for European consumers, and

426 inconvenience and high price were key barriers (Almli et al., 2011; Pieniak et al.,

427 2009). It also corresponds with the positive association between traditional food

428 consumption in Europe and the original FCM dimensions Familiarity and Natural

429 content, although in our study two items of the dimension Natural content were

430 classified into a new FCM dimension Food safety concern, while a negative link was

431 found with the dimension Convenience (Pieniak et al., 2009). Not surprisingly,

432 traditional food consumers prefer to spend a relative high percentage of income and a

433 long time on (preparing) food, as compared to non-traditional food consumers (Almli

434 et al., 2011; Pieniak et al., 2009; Vanhonacker, Lengard, et al., 2010).

435 Some differences were found with respect to the choice motives for traditional

436 food between European consumers (Pieniak et al., 2009) and mainland Chinese

437 consumers. Whereas Weight control and Healthiness were two negative factors for

438 European consumers to choose traditional food (Pieniak et al., 2009), the dimension

439 Health concern was not found to have a significant relationship in our study. This

440 may be due to differences in dietary patterns, culture and customs between China and

441 Europe. A traditional Chinese dietary pattern, for instance, contains more vegetables,

442 less meat, less calories and less fat than that of Europeans (Behar, 1976; Wan, 1995).

443 This may have resulted in more traditional foods with less unhealthy ingredients in 
445 consumers' purchase intentions toward traditional food in Shanghai, while this FCM

446 dimension was not included in previous FCQ surveys on European consumers'

447 traditional food choice motives (Pieniak et al., 2009). As Mood reflects consumers'

448 emotional feelings toward food products (Steptoe et al., 1995), this finding reveals

449 that traditional food was not chosen by consumers for emotional reasons, such as

450 stress relieve.

451 When looking at European food, three important motivation factors directly or

452 indirectly influenced mainland Chinese consumers' choice: Mood (positively related),

453 Sensory appeal (positively related) and Time or money saving (negatively related).

454 Sensory appeal was found to have a strong and direct influence on mainland Chinese

455 consumers' choice for European food. This confirms the importance of appetizing or

456 taste reassurance in China in order to try or consume Western-style foods, as reported

457 previously by other studies (Chang et al., 2010; Curtis et al., 2007). Further, Mood

458 was an important reason for choosing European food. This corresponds with previous

459 studies showing that Chinese consumers often consume Western-style foods for the

460 aesthetic and emotional pleasures as well as to experience Western cultures (Curtis et

461 al., 2007; Zhou \& Hui, 2003). In addition, Time or money saving was considered as a

462 barrier (negatively related) for purchase intentions toward European food, which fits

463 with the current reality of Western-style foods in mainland Chinese markets. The

464 imported Western-style food products are often much more expensive than Chinese

465 local food products. For most of mainland Chinese consumers, such foods are not a 

defined as 'a local food product imported from Europe or the food with European style or flavor that can be consumed in restaurants or other places of China', rather than convenient or, even, fast foods. Participants may directly associate the concept of

470 European food with the high-priced imported foods or the foods in high-end Western restaurants. Therefore, it is reasonable that Chinese consumers who attach importance to saving money or time when buying food are less willing to choose European food. There were also differences in consumer behavior toward traditional food and 474 European food between the two cities. Mood and Time or money saving appeared to 475 be significant for consumers to choose both food types in Shanghai, while these two 476 factors did not play a role in the Xi'an sample. This may be caused by the discrepancy 477 between the development levels of the two cities or regions. Hence, getting relaxed or 478 saving time or money from foods may become important for Shanghai people in order 479 to deal with the high-pressure style of daily life. For either traditional or European foods, Sensory appeal was a direct and strong factor driving mainland Chinese consumers' purchase intention. Indeed, 482 sensory pleasure, such as tasty, nice smell and good appearance, is considered of great 483 importance for consumer food preferences in China (Dang, 2010; Wan, 1995). In this 484 respect, when Western food marketers aim to exploit the mainland Chinese consumer 485 market, they could employ sensory-related marketing strategies, for instance, by 486 adjusting the sensory attributes (e.g. taste and appearance) of their products in line 487 with specific (regional) food patterns and consumer requirements. Similarly as our 
finding that one needs to adapt the FCM construct to the specific cultural setting, one 489 needs also to adapt its marketing strategy when aiming to enter a different food 490 market. By providing a better understanding of Chinese consumers' food choice 491 motives, this study has contributed to provide an answer to both issues.

493 nature of our survey, i.e. an online questionnaire, and the relatively small number of 494 participants involved, our sample did not fully represent the demographic 495 characteristics of mainland China as well as the two particular cities. Additionally, 496 this study focused on FCQ-based items and dimensions. It is necessary for future 497 research to also focus or integrate factors outside the FCQ, such as Origin of food, 498 Food neophobia and Symbolic values. Furthermore, as we focused on traditional food 499 and European food as two general types of food, we did not analyze whether our 500 novel construct is valid for specific food categories. Moreover, due to the fact that our 501 FCM construct is based on PCA, our data should not be used for a CFA (Biddle \& 502 Marlin, 1987; Breckler, 1990; Wu, 2009). A CFA might be conducted for the new 503 construct in future FCQ-based studies for mainland China. In addition, given the 504 scope of this study, our SEM model (Figure 2) was used for a path analysis to address 505 the lack of understanding of Chinese consumers' motives for traditional food and 506 European food, whereas developing a theoretical model for those food choices was 507 not part of this study. 
Anderson, J. C., \& Gerbing, D. W. (1988). Structural equation modeling in practice: A review and recommended two-step approach. Psychological Bulletin, 103(3), 411-423.

Ajzen, I. (1991). The theory of planned behavior. Organizational Behavior and Human Decision Processes, 50(2), 179-211.

Alice, T. (2013). China's packaged food market: capitalising on the rising demand for premium imported items. Available at the Website: <http://economists-pickresearch.hktdc.com/business-news/article/Research-Articles/China-spackaged-food-market-capitalising-on-the-rising-demand-for-premiumimported-items/rp/en/1/1X000000/1X09V7A5.htm>. Visited January 2014.

Alinna (2013). China has become the biggest wine export market of EU. Available at the Website: < http://www.wine.cn/html/201306/20677.html>. Visited January 2014.

Almli, V. L., Verbeke, W., Vanhonacker, F., Næs, T., \& Hersleth, M. (2011). General image and attribute perceptions of traditional food in six European countries. Food Quality and Preference, 22(1), 129-138.

Behar, M. (1976). European diets vs traditional foods. Food Policy, 1(5), 432-435.

Biddle, B. J., \& Marlin, M. M. (1987). Causality, confirmation, credulity, and structural equation modeling. Child Development, 58(1), 4-17.

Breckler, S. J. (1990). Applications of covariance structure modeling in psychology: Cause for concern?. Psychological Bulletin, 107(2), 260-273.

Brunner, T. A., van der Horst, K., \& Siegrist, M. (2010). Convenience food products. Drivers for consumption. Appetite, 55(3), 498-506.

Byrne, B. M. (2001). Structural equation modeling with AMOS: Basic concepts, applications and programming. New Jersey: Lawrence Erlbaum Associates.

Cai, X. M., \& Situ, S. J. (2006). A review on the studies of food culture from geographical perspective. Yunnan Geographic Environment Research, (05), 83-88.

Chang, R. C., Kivela, J., \& Mak, A. H. (2010). Food preferences of Chinese tourists. Annals of Tourism Research, 37(4), 989-1011.

Chen, M. F. (2007). Consumer attitudes and purchase intentions in relation to organic foods in Taiwan: moderating effects of food-related personality traits. Food Quality and Preference, 18(7), 1008-1021.

Chen, M. F. (2011). The gender gap in food choice motives as determinants of consumers' attitudes toward GM foods in Taiwan. British Food Journal, 113(6), 697-709.

Cheng, C. K. (1994). The culture of Chinese diet: Regional differentiation and developing trends. Acta Geographica Sinica, 49(3), 226-235.

Curtis, K. R., Mccluskey, J. J., \& Wahl, T. I. (2007). Consumer preferences for western-style convenience foods in China. China Economic Review, 18(1), 114.

Dang, B. H. (2010). Research on the mergence of Chinese and western food culture. 
Journal of Chongqing University of Science and Technology(Social Sciences Edition), (10), 160-161.

Eertmans, A., Victoir, A., Notelaers, G., Vansant, G., \& Van den Bergh, O. (2006). The Food Choice Questionnaire: Factorial invariant over western urban populations? Food Quality and Preference, 17(5), 344-352.

Fotopoulos, C., Krystallis, A., Vassallo, M., \& Pagiaslis, A. (2009). Food Choice Questionnaire (FCQ) revisited. Suggestions for the development of an enhanced general food motivation model. Appetite, 52(1), 199-208.

Guerrero, L., Claret, A., Verbeke, W., Enderli, G., Zakowska-Biemans, S., Vanhonacker, F., Hersleth, M. (2010). Perception of traditional food products in six European regions using free word association. Food Quality and Preference, 21(2), 225-233.

Guerrero, L., Claret, A., Verbeke, W., Vanhonacker, F., Enderli, G., Sulmont-Rossé, C., Guàrdia, M. D. (2012). Cross-cultural conceptualization of the words Traditional and Innovation in a food context by means of sorting task and hedonic evaluation. Food Quality and Preference, 25(1), 69-78.

Guerrero, L., Guardia, M. D., Xicola, J., Verbeke, W., Vanhonacker, F., ZakowskaBiemans, S., Hersleth, M. (2009). Consumer-driven definition of traditional food products and innovation in traditional foods. A qualitative cross-cultural study. Appetite, 52(2), 345-354.

Hair, J., Black, W., Babin, B., \& Anderson, R. (2014). Multivariate data analysis: Pearson new international edition (Seventh ed.). United States of America: Pearson Education Limited.

Hawkins, D., \& Mothersbaugh, D. (2009). Consumer behavior building marketing strategy. Boston: McGraw-Hill Irwin.

He, L. (2013). Analysis of cultural diference between the south and the north in China: Taking the history and geography on Introduction to Chinese culture as an example. Jin Tian, (7), 292.

Honkanen, P. (2010). Food preference based segments in Russia. Food Quality and Preference, 21(1), 65-74.

Honkanen, P., \& Frewer, L. (2009). Russian consumers' motives for food choice. Appetite, 52(2), 363-371.

Hu, W., Cox, L. J., \& Edwards, Q. A. (2007). The market potential for gift baskets of Hawaiian food products in China. Agribusiness, 23(4), 553-565.

$\mathrm{Hu}$, L. t., \& Bentler, P. M. (1999). Cutoff criteria for fit indexes in covariance structure analysis: Conventional criteria versus new alternatives. Structural Equation Modeling: A Multidisciplinary Journal, 6(1), 1-55.

Januszewska, R., Pieniak, Z., \& Verbeke, W. (2011). Food choice questionnaire revisited in four countries. Does it still measure the same? Appetite, 57(1), 9498.

Johansen, S. B., Næs, T., \& Hersleth, M. (2011). Motivation for choice and healthiness perception of calorie-reduced dairy products. A cross-cultural study. Appetite, 56(1), 15-24.

Klein, J. G., Ettenson, R., \& Morris, M. D. (1998). The Animosity Model of Foreign 
Product Purchase: An empirical test in the People's Republic of China. Journal of Marketing, 62(1), 89-100.

Kornelis, M., Herpen, E. v., Lans, I. v. d., \& Aramyan, L. (2010). Using non-food information to identify food-choice segment membership. Food Quality and Preference, 21(5), 512-520.

Li, X., Lai, C. T., Harrill, R., Kline, S., \& Wang, L. Y. (2011). When east meets west: An exploratory study on Chinese outbound tourists' travel expectations. Tourism Management, 32(4), 741-749.

Liu, S., Smith, J. R., Liesch, P. W., Gallois, C., Ren, Y., \& Daly, S. (2011). Through the lenses of culture Chinese consumers' intentions to purchase imported products. Journal of Cross-Cultural Psychology, 42(7), 1237-1250.

Liu, R., Pieniak, Z., \& Verbeke, W. (2013).Consumers' attitude and behaviour toward safe food in China: A review. Food Control, 33(1), 93-104.

Liu, R., Pieniak, Z., \& Verbeke, W. (2014). Food-related hazards in China: Consumers' perceptions of risk and trust in information sources. Food Control, 46, 291-298.Lupton, D. (1994). Food, memory and meaning: the symbolic and social nature of food events. The Sociological Review, 42(4), 664-685.

Marsh, H. W., \& Balla, J. (1994). Goodness of fit in confirmatory factor analysis: The effects of sample size and model parsimony. Quality and Quantity, 28(2), 185217.

McDonald, R. P., \& Ho, M. H. R. (2002). Principles and practice in reporting structural equation analyses. Psychological Methods, 7(1), 64.

Milošević, J., Žeželj, I., Gorton, M., \& Barjolle, D. (2012). Understanding the motives for food choice in Western Balkan countries. Appetite, 58(1), 205-214.

National Bureau of Statistics of the People's Republic of China. (2013). China stastistical yearbook 2013. Beijing: China Statistics Press.

Olsen, S. O., Scholderer, J., Brunsø, K., \& Verbeke, W. (2007). Exploring the relationship between convenience and fish consumption: a cross-cultural study. Appetite, 49(1), 84-91.

Ortega, D. L., Wang, H. H., Wu, L., \& Olynk, N. J. (2011). Modeling heterogeneity in consumer preferences for select food safety attributes in China. Food Policy, 36(2), 318-324.

Pieniak, Z., Verbeke, W., Vanhonacker, F., Guerrero, L., \& Hersleth, M. (2009). Association between traditional food consumption and motives for food choice in six European countries. Appetite, 53(1), 101-108.

Pingali, P. (2007). Westernization of Asian diets and the transformation of food systems: Implications for research and policy. Food Policy, 32(3), 281-298.

Pohjanheimo, T., Paasovaara, R., Luomala, H., \& Sandell, M. (2010). Food choice motives and bread liking of consumers embracing hedonistic and traditional values. Appetite, 54(1), 170-180.

Prescott, J., Young, O., O'Neill, L., Yau, N. J. N., \& Stevens, R. (2002). Motives for food choice: a comparison of consumers from Japan, Taiwan, Malaysia and New Zealand. Food Quality and Preference, 13(7), 489-495.

Pula, K., Parks, C. D., \& Ross, C. F. (2014). Regulatory focus and food choice 
motives. Prevention orientation associated with mood, convenience, and familiarity. Appetite, 78, 15-22.

Qiao, G. H., Guo, T., \& Klein, K. K. (2012). Melamine and other food safety and health scares in China: Comparing households with and without young children. Food Control, 26(2), 378-386.

Rigdon, E. E. (1995). A necessary and sufficient identification rule for structural models estimated in practice. Multivariate Behavioral Research, 30(3), 359383.

Roos, E., Lehto, R., \& Ray, C. (2012). Parental family food choice motives and children's food intake. Food Quality and Preference, 24(1), 85-91.

Sproesser, G., Strohbach, S., Schupp, H., \& Renner, B. (2011). Candy or apple? How self-control resources and motives impact dietary healthiness in women. Appetite, 56(3), 784-787.

Steptoe, A., Pollard, T. M., \& Wardle, J. (1995). Development of a measure of the motives underlying the selection of food: the food choice questionnaire. Appetite, 25(3), 267-284.

Sun, X., \& Collins, R. (2004). A comparison of attitudes among purchasers of imported fruit in Guangzhou and Urumqi, China. Food Quality and Preference, 15(3), 229-237.

Sun, Y. H. (2012). Discussion on the influence of geographical difference to the northern and southern Chinese. Outside Reading, (20), 243-243.

Tang, F. (2013). The dilemma of food safety in China and perspectives. In China Green Development Index Report 2011 (pp. 441-447). Springer Berlin Heidelberg.

Vanhonacker, F., Lengard, V., Hersleth, M., \& Verbeke, W. (2010). Profiling European traditional food consumers. British Food Journal, 112(8), 871-886.

Vanhonacker, F., Verbeke, W., Guerrero, L., Claret, A., Contel, M., Scalvedi, L., \& Hersleth, M. (2010). How European consumers define the concept of traditional food: Evidence from a survey in six countries. Agribusiness, 26(4), 453-476.

Verbeke, W., \& Lopez, G. P. (2005). Ethnic food attitudes and behaviour among Belgians and Hispanics living in Belgium. British Food Journal, 107(11), 823-840.

Vyth, E. L., Steenhuis, I. H., Vlot, J. A., Wulp, A., Hogenes, M. G., Looije, D. H., Seidell, J. C. (2010). Actual use of a front-of-pack nutrition logo in the supermarket: consumers' motives in food choice. Public Health Nutrition, $13(11), 1882$.

Wan, J. Z. (1995). Comparison of Chinese and Western diet culture. Forum on Chinese Culture, (3), 95-100.

Wang, O., Gellynck, X., Liu, H., Liu, H., Zhang, H., Vanhonacker, F., Verbeke, W. (2014). Perceptual dimensions of traditional food and European food by Chinese consumers. Working paper Ghent University, Department of Agricultural Economics. Ghent: Ghent University. 
685 World Bank. (2014). GDP per capita, PPP (current international \$). Available at the 686 Website:

$687<$ http://data.worldbank.org/indicator/NY.GDP.PCAP.PP.CD?order=wbapi_dat a_value_2012+wbapi_data_value+wbapi_data_value-last\&sort $=$ desc

$690 \mathrm{Wu}, \mathrm{M} . \mathrm{L}$. (2009). Structural equation modeling: the operation and application of AMOS. Chongqing: Chongqing University Press.

Zakowska-Biemans, S. (2011). Polish consumer food choices and beliefs about organic food. British Food Journal, 113(1), 122-137.

Žeželj, I., Milošević, J., Stojanović, Ž., \& Ognjanov, G. (2012). The motivational and informational basis of attitudes toward foods with health claims. Appetite, 59(3), 960-967.

Zhang, H. X., An, Y. F., \& Zhang, W. S. (2013). Indenfication, evaluation and management of food safety risk: a study based on food safety events in China. Inquiry into Economic Issues, (6), 135-141.

Zhang, S., Zhang, F., Tang, W., Zou, C., \& Su, Q. (2009). Geographic research of food culture in China. Yunnan Geographic Environment Research, 21(2), 2731.

Zhang, X., Guo, H., Zhao, L., Sun, W., Zeng, S., Lu, X., Ren, F. (2011). Sensory profile and Beijing youth preference of seven cheese varieties. Food Quality and Preference, 22(1), 101-109.

Zhao, R. G. (2003). Chinese dietary culture overview (Vol. 6). Beijing: Higher Education Press.

Zhou, L., \& Hui, M.K. (2003). Symbolic value of foreign products in the People's Republic of China. Journal of International Marketing, 11(2), 36-58. 
1 Table 1. Detailed socio-demographic characteristics of the samples

\begin{tabular}{llll}
\hline & Pooled sample & Shanghai & Xi'an \\
\hline Sample size $(n=)$ & 541 & 259 & 282
\end{tabular}

Gender

$\begin{array}{llll}\text { Male } & 42.7 \% & 38.6 \% & 46.5 \% \\ \text { Female } & 57.3 \% & 61.4 \% & 53.5 \%\end{array}$

Age

$\begin{array}{llrl}\text { Mean } & 35.63 & 37.16 & 34.23 \\ \text { Range } & 19-68 & 19-59 & 19-68 \\ 19-30 & 32.2 \% & 24.3 \% & 39.4 \% \\ 31-40 & 31.2 \% & 34.4 \% & 28.3 \% \\ >40 & 36.6 \% & 41.3 \% & 32.3 \%\end{array}$

Financial Situation

Difficult-

$\begin{array}{lccc}\text { Moderate } & 10.4 \% & 5.4 \% & 14.9 \% \\ \text { Moderate } & 24 \% & 20.1 \% & 27.7 \% \\ \text { Moderate-Well } & & & \\ \text { off } & 65.6 \% & 74.5 \% & 57.4 \%\end{array}$

Occupation

$\begin{array}{lccc}\begin{array}{l}\text { Managing } \\ \text { employee }\end{array} & 31.8 \% & 36.7 \% & 27.3 \% \\ \begin{array}{l}\text { Salaried } \\ \text { employee }\end{array} & 34.6 \% & 44 \% & 25.9 \% \\ \text { Student } & 17.7 \% & 5.4 \% & 29.1 \% \\ \text { Skilled worker } & 6.3 \% & 7.3 \% & 5.3 \% \\ \text { Other } & 9.6 \% & 6.6 \% & 12.4 \%\end{array}$


5 Table 2. Selected FMC items and original dimensions

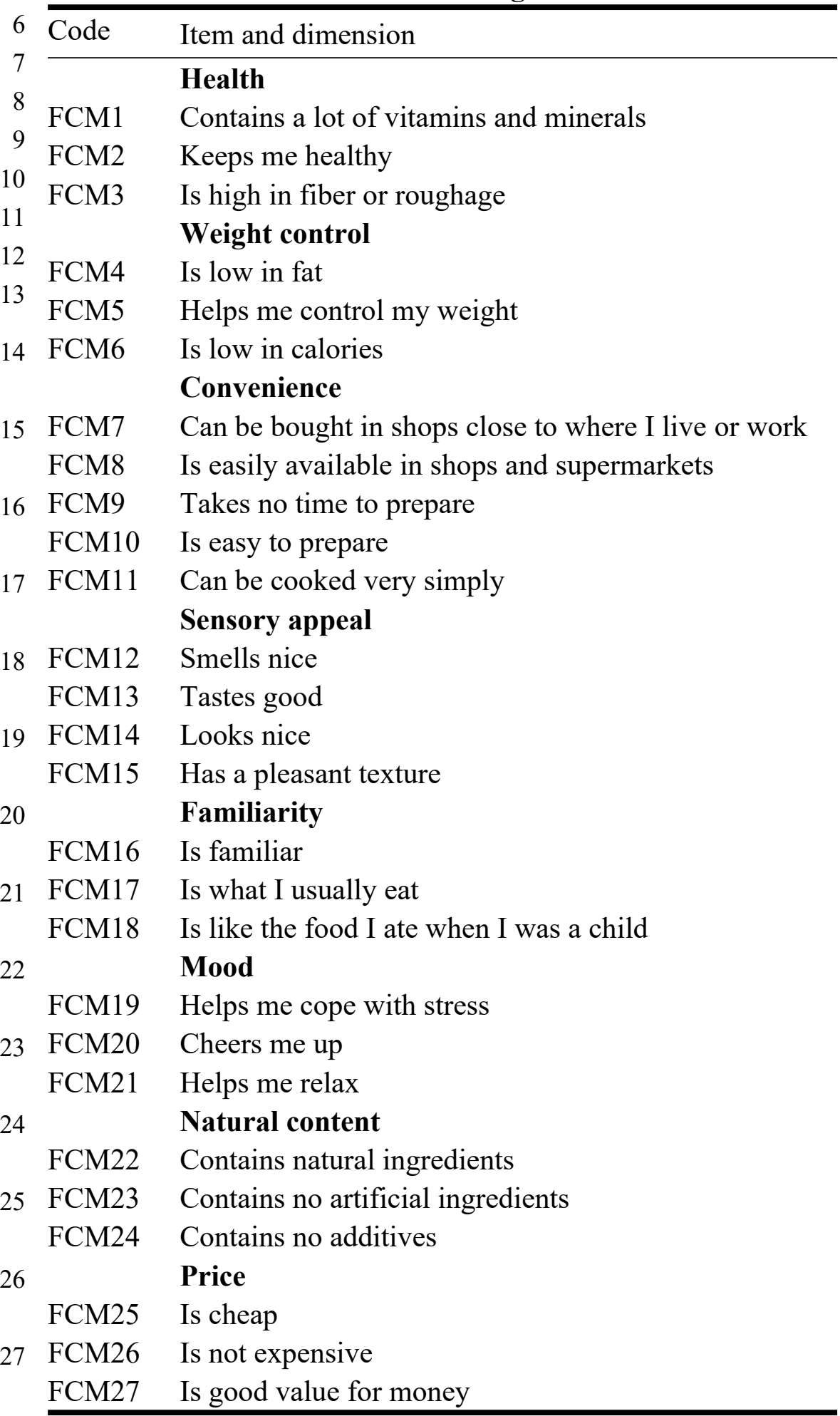


31 Table 3. Measurement items for attitudes and purchase intentions toward

32 traditional food and European food

33 Code Item and dimension

ATT Attitudes toward traditional food

34 ATT1 unhappy/happy

ATT2 dull/excited

35 ATT3 terrible/delighted

ATE Attitudes toward European food

36 ATE1 unhappy/happy

ATE2 dull/excited

37 ATE3 terrible/delighted

WTBT Willingness to buy (purchase intentions) traditional food

38 WTBT1 I would never buy a traditional food (R).

WTBT2 Whenever available, I would prefer to buy traditional food.

39 WTBT3 Whenever possible, I avoid buying traditional food (R).

WTBE Willingness to buy (purchase intentions) European food

40 WTBE1 I would never buy a European food (R).

WTBE2 Whenever available, I would prefer to buy European food.

41 WTBE3 Whenever possible, I avoid buying European food (R).

42

43

44 
46 Table 4. Goodness-of-fit indices for confirmatory factor analysis

\begin{tabular}{lrrr}
\hline & Pooled sample & Shanghai & Xi'an \\
\hline Chi-square & 1442.138 & 940.833 & 910.213 \\
DF & 296 & 296 & 296 \\
NC & 4.872 & 3.178 & 3.075 \\
CFI & 0.815 & 0.792 & 0.808 \\
RMSEA & 0.085 & 0.092 & 0.086 \\
IFI & 0.816 & 0.796 & 0.811 \\
\hline
\end{tabular}

$* p<0.001$ for the pooled sample and the samples of each city.

48

49

50

51

52

53

54

55

56

57

58

59

60

61

62

63

64

65

66

67

68

69

70

71

72

73

74

75

76 
Table 5. Summary of the PCA, with rotated factor loadings $(>0.50)$ of items and the Cronbach's $\alpha$ scores of dimensions

\begin{tabular}{|c|c|c|c|}
\hline Code & Item and dimension & $\begin{array}{l}\text { Rotated factor } \\
\text { loading }\end{array}$ & $\begin{array}{c}\text { Cronbach's } \\
\alpha\end{array}$ \\
\hline$\overline{\mathrm{HC}}$ & Health concern & & 0.894 \\
\hline FCM1 & Contains a lot of vitamins and minerals & 0.756 & \\
\hline FCM4 & Is low in fat & 0.754 & \\
\hline FCM5 & Helps me control my weight & 0.747 & \\
\hline FCM3 & Is high in fiber or roughage & 0.746 & \\
\hline FCM6 & Is low in calories & 0.732 & \\
\hline FCM2 & Keeps me healthy & 0.701 & \\
\hline FCM22 & Contains natural ingredients & 0.667 & \\
\hline TMS & Time or money saving & & 0.775 \\
\hline FCM25 & Is cheap & 0.796 & \\
\hline FCM26 & Is not expensive & 0.739 & \\
\hline FCM9 & Takes no time to prepare & 0.657 & \\
\hline FCM10 & Is easy to prepare & 0.587 & \\
\hline FCM11 & Can be cooked very simply & 0.555 & \\
\hline SA & Sensory appeal & & 0.739 \\
\hline FCM12 & Smells nice & 0.722 & \\
\hline FCM13 & Tastes good & 0.713 & \\
\hline FCM14 & Looks nice & 0.659 & \\
\hline FCM15 & Has a pleasant texture & 0.637 & \\
\hline $\mathbf{A F}$ & Availability and familiarity & & 0.678 \\
\hline FCM16 & Is familiar & 0.677 & \\
\hline FCM7 & $\begin{array}{l}\text { Can be bought in shops close to where I } \\
\text { live or work }\end{array}$ & 0.601 & \\
\hline FCM17 & Is what I usually eat & 0.574 & \\
\hline FCM8 & $\begin{array}{l}\text { Is easily available in shops and } \\
\text { supermarkets }\end{array}$ & 0.550 & \\
\hline $\mathbf{M}$ & Mood & & 0.743 \\
\hline FCM19 & Helps me cope with stress & 0.746 & \\
\hline FCM20 & Cheers me up & 0.739 & \\
\hline FCM21 & Helps me relax & 0.731 & \\
\hline FSC & Food safety concern & & 0.826 \\
\hline FCM23 & Contains no artificial ingredients & 0.783 & \\
\hline FCM24 & Contains no additives & 0.661 & \\
\hline
\end{tabular}


84 Table 6. Path analysis goodness-of-fit indices (pooled sample, $\mathbf{n = 5 4 1}$ )

\begin{tabular}{lr}
\hline & Pooled sample \\
\hline Chi-square & 1515.278 \\
DF & 587 \\
NC & 2.581 \\
CFI & 0.901 \\
RMSEA & 0.054 \\
IFI & 0.902 \\
\hline$* p<0.001$ & \\
\end{tabular}




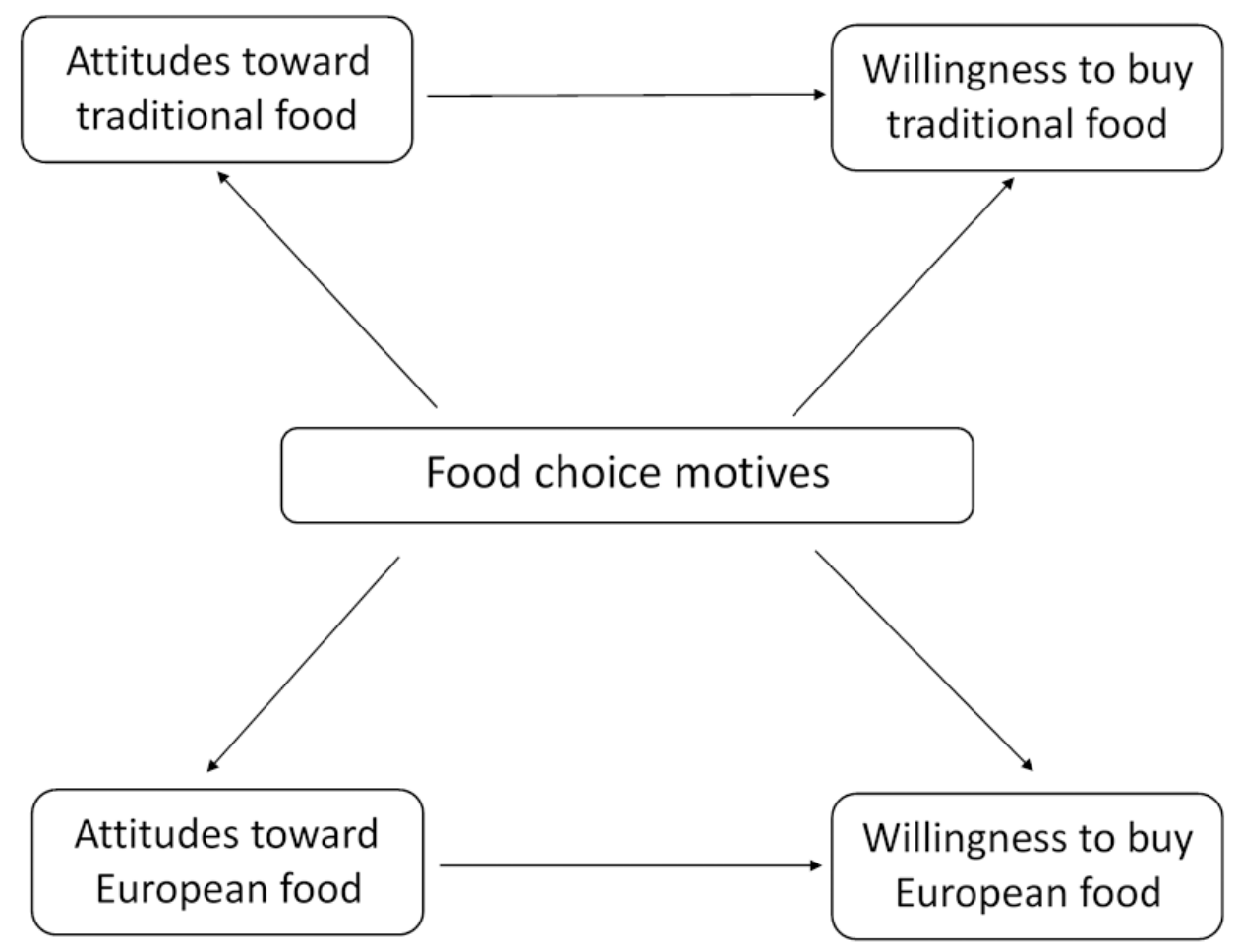

Figure 1. Hypothetical model associating FCMs with attitudes and purchase intentions toward traditional food and European food 


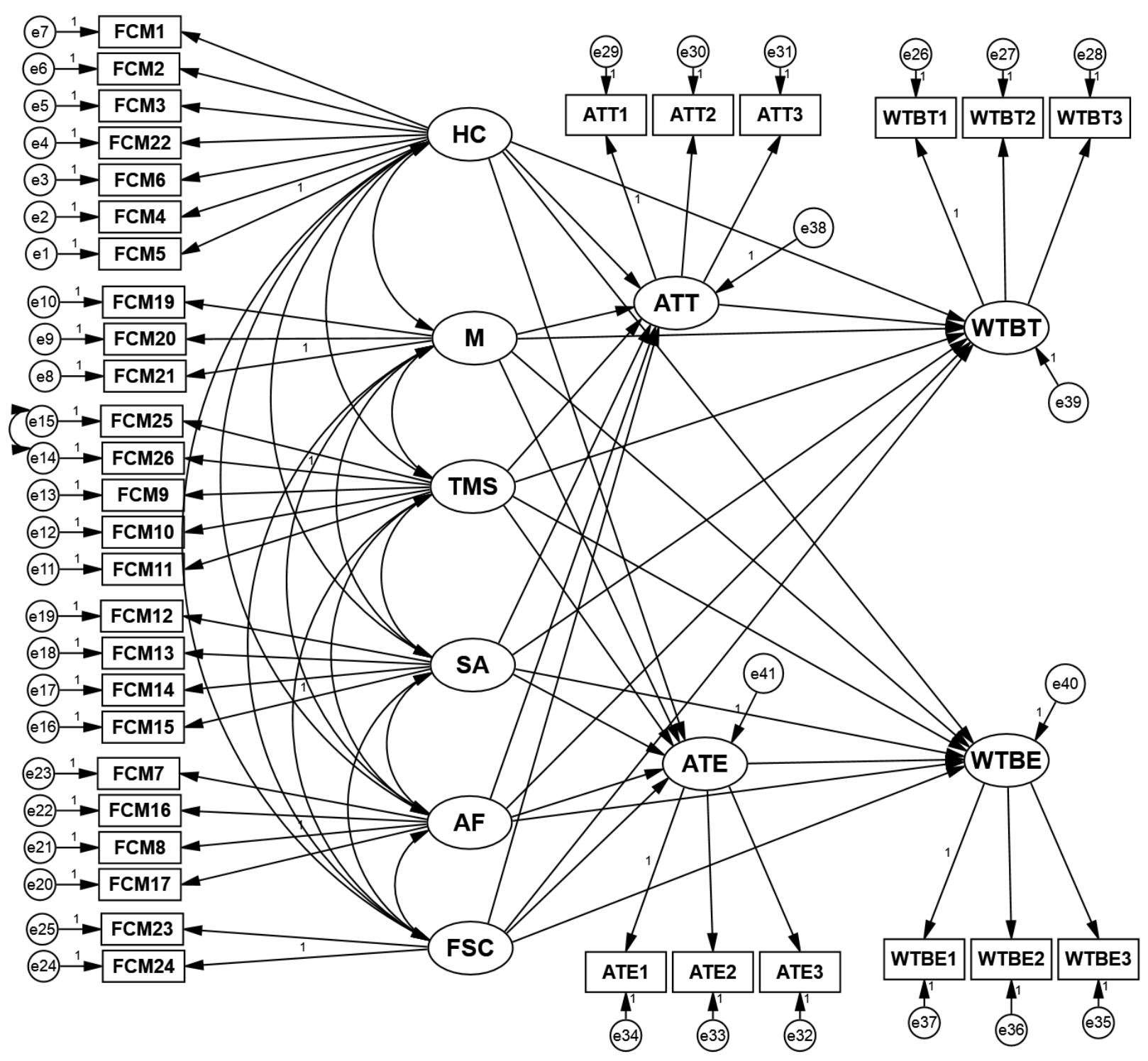




\section{Figure 2. Structural equation model for path analysis using AMOS21}

3 *e1-e41: error variables; FCM1-FCM26 (without FCM 18 and 27): for the codes of the observed variables of FCM items, see Table 2 and

4 Table 5; HC, M, TMS, SA, AF and FSC: for the codes of the latent variables of the six FCM dimensions, see Table 5; ATT WTBT, ATE, WTBE:

5 for the codes of the latent variables of attitudes and purchase intentions toward traditional food and European food, see Table 3; ATT1, ATT2,

6 ATT3, WTBT1, WTBT2, WTBT3, ATE1, ATE2, ATE3, WTBE1, WTBE2, WTBE3: for the codes of the observed variables of attitudes and

7 purchase intentions toward traditional food and European food, see Table 3.

8 


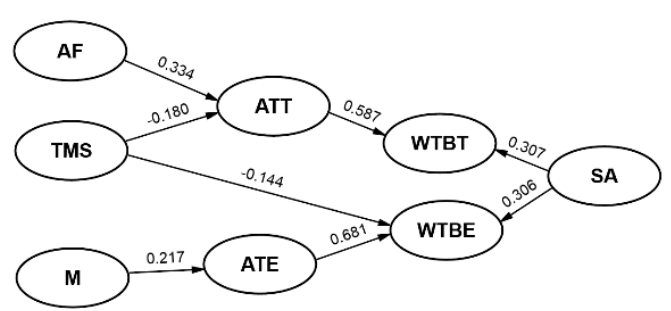

Pooled sample

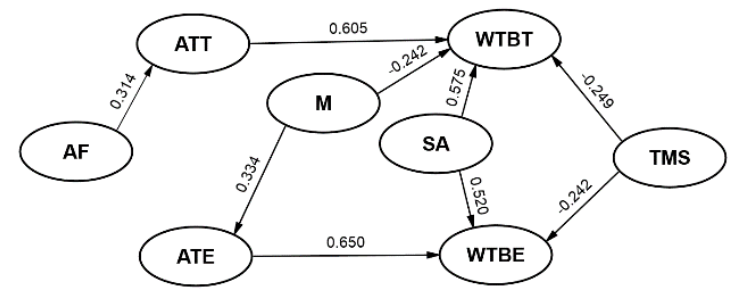

Shanghai

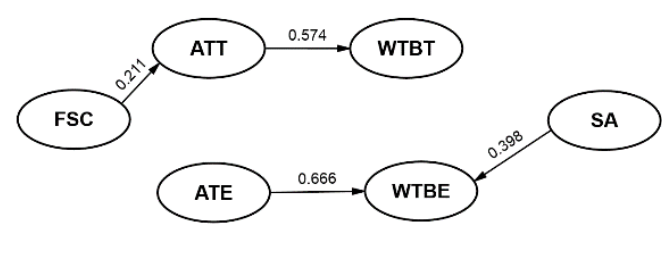

Xi'an

15 Figure 3. Significant paths with standardized regression weights for the three

16 models

$17 * H C, M, T M S, S A, A F$ and FSC: the codes of the latent variables of six FCM

18 dimensions (see Table 5); ATT WTBT, ATE, WTBE: the codes of the latent variables

19 of attitudes and purchase intentions toward traditional food and European food (see

20 Table 3). 